Periodica Polytechnica Mechanical Engineering, 63(2), pp. 75-79, 2019

\title{
Mass Optimization of Gears
}

\author{
Imre Czinege ${ }^{1 *}$ \\ 1 Department of Materials Science and Technology, Faculty of Vehicle Engineering, \\ Széchenyi István University, H-9026 Győr, Egyetem tér 1, Hungary \\ * Corresponding author, e-mail: czinege@sze.hu
}

Received: 26 October 2017, Accepted: 03 November 2018, Published online: 21 February 2019

\begin{abstract}
The paper deals with the mass optimization of gear pairs. The proposed material science based selection strategy uses an extended version of Ashby model, where the minimum value of mass as function of material parameters and density can be calculated. Comparative analyses have proved that applying the method proposed, various gear materials can be classified and ranked. It could be concluded that case or induction hardened steels and titanium alloys with appropriate surface treatment are the best solutions for high quality gear materials. The presented relationships for material parameters and geometry of gears help empirical or heuristic selection of proper materials.
\end{abstract}

Keywords

mass optimization, material selection, Ashby model, gear

\section{Introduction}

Material selection is a key issue in optimal design process. Several design strategies are known from literature [1-5], but the most valuable systematic materials science based method can be regarded to Ashby and his team. A good summary of original theory and practice can be found in [6] but lot of papers extended the possible applications as well [7-11]. The main advantage of Ashby theorem against general selection strategies is that it considers mass optimization, which is very important factor in vehicle design.

The practical use of selection method requires both the appropriate dimensioning equations $[12,13]$ and gear specific material parameters $[14,15]$. Commonly used materials of gears are steels, their properties and heat treatment is well known from the industrial practice [15]. Special attention is needed for other concurrent metals like titanium and magnesium alloys or polymer composite gear materials [16-21].

Regarding the Ashby selection strategy [6], it has four main steps: (a) selection of workpiece type, (b) definition of an appropriately selected objective function, (c) formulation of constraints, (d) development of a proper searching algorithm (sorting procedure). When choosing the appropriate material for a given component, at first the objective function should be defined, followed by the introduction of constraints and free variables. The material properties can be characterized by different numerical indices, like strength-to-density or elastic modulus-to-density ratio. Ranking based on the use of material indices is a commonly accepted guideline for quick selection of materials.

\section{Gear specific material properties}

Two specific parameters are used for dimensioning gear pairs, first is the pitting bearing capacity $\left(\sigma_{H \text {-Lim }}, \mathrm{MPa}\right)$ which characterizes the resistance of material against repeated Hertz-stresses. The second parameter is tooth root strength $\left(\sigma_{F-\text { Lim }}, \mathrm{MPa}\right)$ - it is in correlation with fatigue strength. These material properties can be found in the appropriate tables for commonly used gear materials. For example Fig. 1 shows the dependence of pitting bearing capacity and tooth root strength as function of tooth surface hardness for steels and cast irons. Lower hardness values are belonging to cast irons and normalized steels while higher hardness region shows points of case or induction hardened steels. These charts might be useful if one wish to estimate the gear specific parameters of a steel or cast iron.

Different material groups - steels, polymers, light metals - can be compared by specific indices, where the properties are divided by density. Table 1 and Fig. 2 show two "composite indices", pitting bearing capacity/density and tooth root strength/density ratio. It can be seen that case and induction hardened steels plus titanium alloys have 

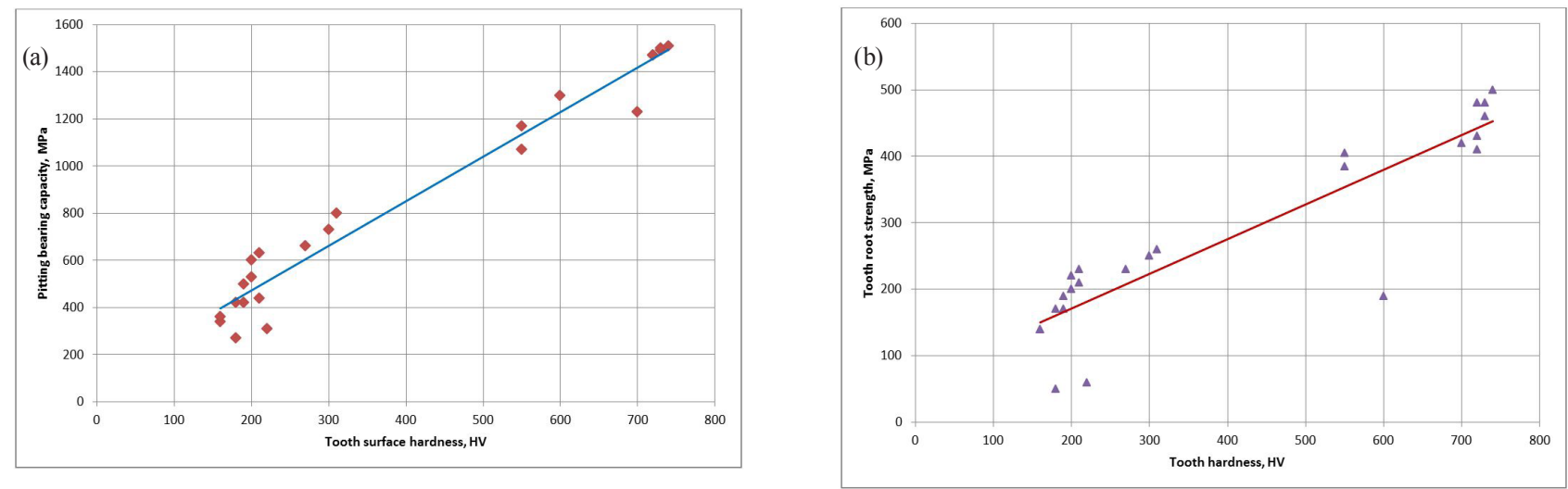

Fig. 1 Correlation between hardness and gear specific parameters

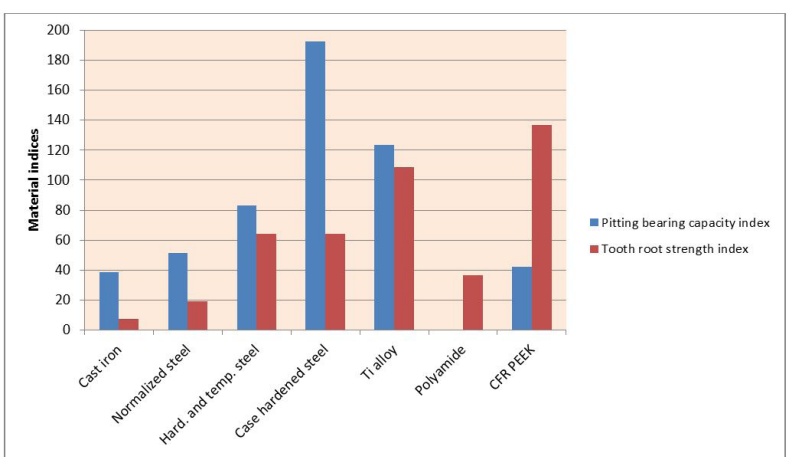

Fig. 2 Comparison of indices

the best pitting bearing capacity index while regarding tooth root strength index, titanium alloys and CFR PEEK composite are the best. The most balanced indices belong to titanium alloys but excellent sliding properties (low friction coefficient) can be reached only with appropriate surface coating [16].

\section{Dimensioning gear pairs}

The basic equations for dimensioning gear pairs are represented by Eq. (1) and Eq. (2). Equation (1) refers to the center distance of gears $\left(a_{\min }, \mathrm{mm}\right)$ and Eq. (2) defines their diametral pitch $\left(m_{\min }\right)$ :

$a_{\min }=C_{a} \sqrt[3]{\frac{P K_{A}(u+1)^{4}}{n\left(\frac{b}{d_{w 1}}\right) \sigma_{H L i m}^{2}}}$

$m_{\min }=C_{m} \frac{P K_{A}(u+1)}{n a_{w} b \sigma_{F L i m} \pi}$.

Gear specific parameters in the equations:

- gear width $(b, \mathrm{~mm})$

- mean diameter $\left(d_{w 1}, \mathrm{~mm}\right)$

- $\operatorname{power}(P, \mathrm{~kW})$
Table 1 Properties and specific indices of some gear materials

\begin{tabular}{lccccc}
\hline & $\begin{array}{c}\sigma_{H} \\
{[\mathrm{MPa}]}\end{array}$ & $\begin{array}{c}\sigma_{F} \\
{[\mathrm{MPa}]}\end{array}$ & $\begin{array}{c}\rho \\
{\left[\mathrm{Mg} / \mathrm{m}^{3}\right]}\end{array}$ & $\sigma_{H} / \rho$ & $\sigma_{F} / \rho$ \\
\hline Cast iron & 300 & 60 & 7.8 & 38.5 & 7.69 \\
Normalized steels & 400 & 150 & 7.8 & 51.3 & 19.2 \\
$\begin{array}{l}\text { Hardened steels } \\
\begin{array}{l}\text { Case and induction } \\
\text { hardened steels }\end{array}\end{array}$ & 650 & 500 & 7.8 & 83.3 & 64.1 \\
$\begin{array}{l}\text { Titanium alloys } \\
\text { Polyamide }\end{array}$ & 580 & 510 & 4.7 & 123 & 108 \\
$\begin{array}{l}\text { CFR PEEK } \\
\text { composite }\end{array}$ & 800 & 260 & 1.9 & 42.1 & 137 \\
\hline
\end{tabular}

- transmission ratio $(u)$

- rotational speed ( $n, 1 / \mathrm{min})$

- constants $\left(C_{a}, C_{m}, K_{A}\right)$

Material parameters:

- pitting bearing capacity $\left(\sigma_{\text {HLim }}, \mathrm{Mpa}\right)$

- tooth root strength $\left(\sigma_{\mathrm{Flim}}, \mathrm{Mpa}\right)$

Fig. 3 illustrates the effect of material parameters on the size of center distance (Fig. 3(a)) and diametral pitch (Fig. 3(b)). It should be noted that on Fig. 3(a) center distance ratio is displayed, by definition it is actual center distance related to $a_{\text {ref }}=100 \mathrm{~mm}$. These figures offer a quick estimation how the material parameters effect dimensions, mass and volume.

Further analysis can be carried out on the volume and mass using Eq. (3) which shows the volume of gear pair for an optional $u$ transmission ratio:

$V=\left(\frac{a}{1+u}\right)^{2} * \pi * b+\left(\frac{u a}{1+u}\right)^{2} * \pi * b$.

Using Eq. (3) a volume ratio index can be derived as the quotient of volume $\mathrm{V}$ and $V_{1}$ belonging to $u=1$ transmission ratio: 

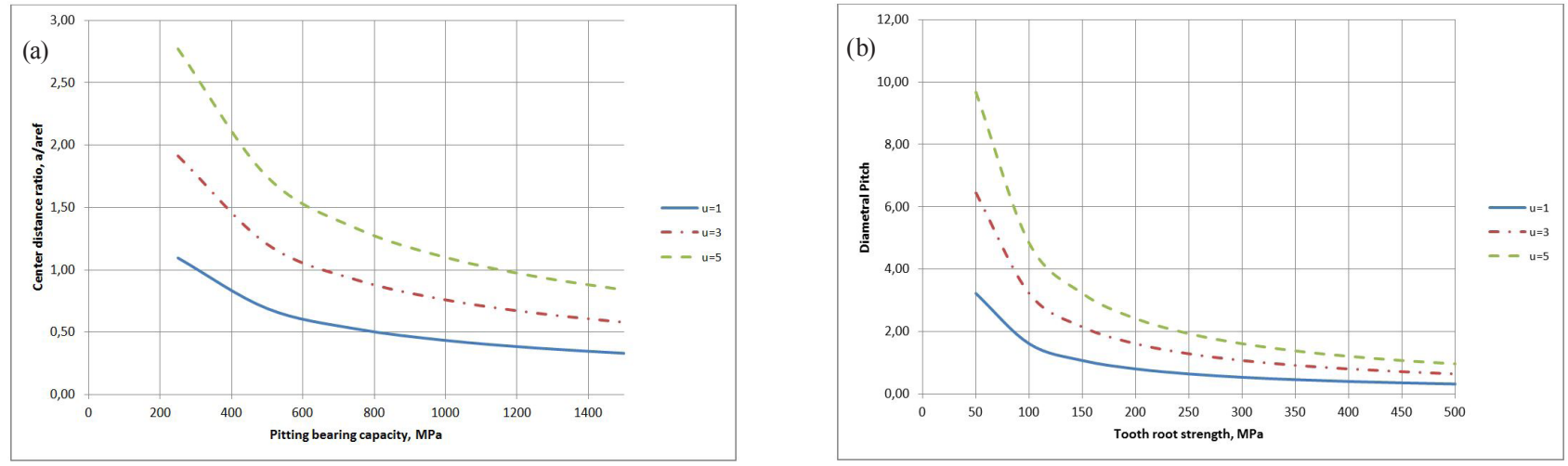

Fig. 3 Correlation among material parameters and gear dimensions

$\frac{V}{V_{1}}=\left(\left(\frac{a}{1+u}\right)^{2}+\left(\frac{u a}{1+u}\right)^{2}\right) * \frac{2}{a^{2}}$.

Fig. 4(a) shows the volume ratio index as function of transmission ratio; it is clear that as the transmission ratio increases from 1 to 5, volume of gear pair will be greater with $\sim 50 \%$. Fig. 4(b) illustrates the change in relative volume to center distance ratio (reference $a=100 \mathrm{~mm}$ ).

The newly developed indices which can be seen in Table 1 and Figs. 1 to 4 help the engineer in empirical and heuristic design as they indicate the direction of changes and give a certain ranking of materials, but they do not offer a real scientific approach to material selection process.

\section{Development of Ashby-model for gear pairs}

Well known example is presented for beam in [6], where objective is to minimize mass. In this paper a new model will be developed for gears, which is not known from literature. Namely for example in [1] contact stress (pitting bearing capacity) is associated with Brinell hardness and endurance limit of tooth with ultimate tensile strength, but materials are ranked based on these properties without optimization of mass. Similarly in [5] publication only material parameters are composed with weighting factors - not considering torque, power and geometric parameters. The new model only uses the logic of the Ashby model but minimum mass criteria are fitted to gear parameters. The corner stones of material selection for gear pairs are the followings:

- Workpiece: gear pair (transfer torque and power)

- Objective function: mass minimization

- Constrains: power and other parameters $(u, n)$

- Free variables: dimensions and material parameters

- center distance of gears + pitting bearing capacity

- diametral pitch + tooth root strength

Considering Eq. (1) and Eq. (2) two criteria can be derived for minimum mass $\left(M_{\min }\right)$ using the volume of gear pair and density of material. At first Eq. (1) and Eq. (3) are combined to set up minimal mass for pitting bearing capacity (Eq. (5)) after that similarly Eq. (2) and Eq. (3) give
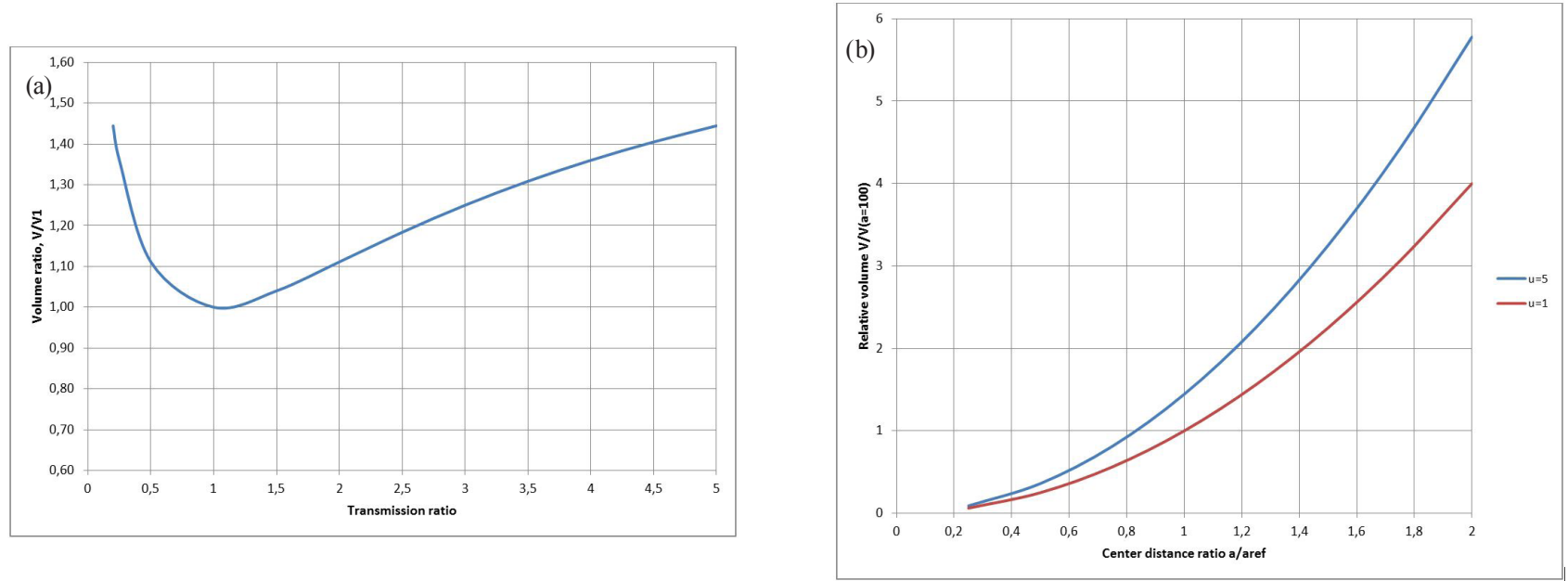

Fig. 4 Correlation among geometric parameters of gears 

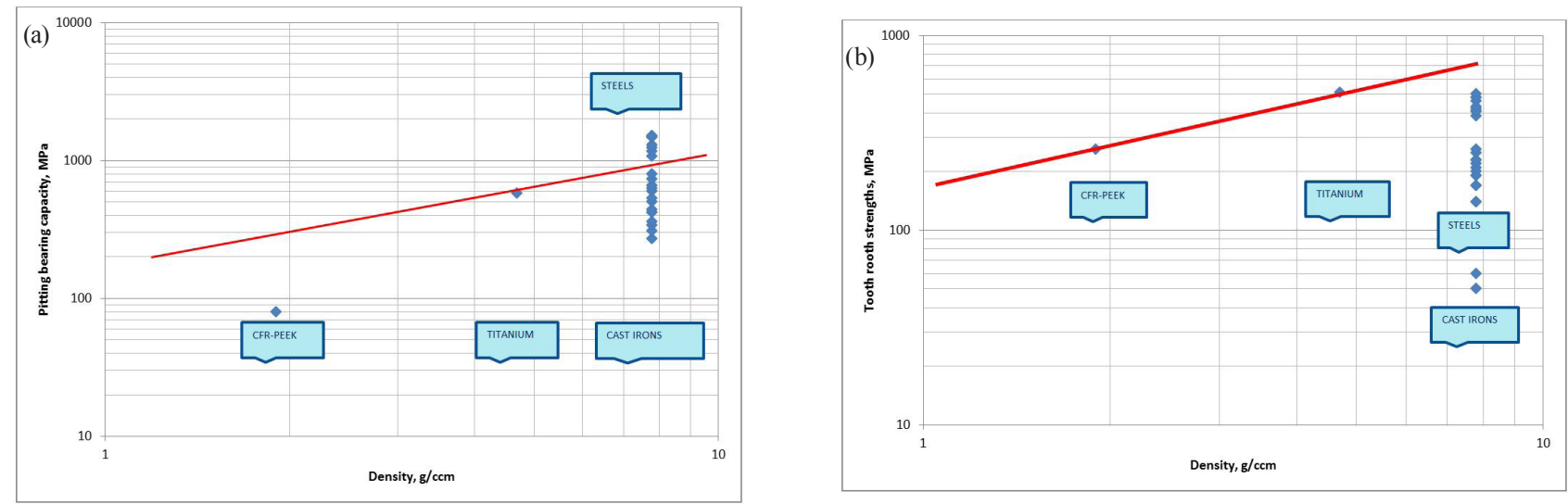

Fig. 5 Selection charts for gear materials

tooth root strength criteria (Eq. (6)). In each cases center distance of gears $\left(a_{\min }\right)$ was eliminated from the equations.

$$
\begin{aligned}
& M_{H, \min }=V * \rho=C_{a}\left(\frac{P}{n}\right)^{\frac{2}{3}} *(1+u)^{\frac{4}{3}} b \pi * \frac{\rho}{\sigma_{H}^{4 / 3}} \\
& M_{F, \min }=V^{*} \rho=\frac{c_{F}^{2} P^{2}}{n^{2}} * \frac{1+u^{2}}{m^{2} b \pi} * \frac{\rho}{\sigma_{F}^{2}}
\end{aligned}
$$

Both equations show three main groups of parameters [6] separated by multiplication sign $(*)$. The first set shows the functional requirements, second group represents the geometrical parameters and third one contains the material characteristic. From Eq. (5) it follows that mass is minimal if $\sigma_{H}^{4 / 3} / \rho$ is maximal, moreover, from the Eq. (6) for tooth root strength it can be concluded that the lightest gear is made of the material with the greatest value of $\sigma_{F}^{2} / \rho$. Graphic illustration of material properties as function of density can be seen on Fig. 5(a) and 5(b). It should be noted that in the original material selection charts the different material groups (clusters) are represented by areas, but in this case the points of gear materials are displayed and only density selects different gear material groups from each other. Strait lines indicate the equivalent materials, the slope of lines can be derived from the power of $\sigma_{H}$ and $\sigma_{F}(4 / 3$ and 2 respectively).

Fig. 5(a) shows that from viewpoint of pitting bearing capacity titanium and hardened steels are the best choice,

\section{References}

[1] Das, D., Bhattacharya, S., Sarkar, B. "Decision-based designdriven material selection: A normative-prescriptive approach for simultaneous selection of material and geometric variables in gear design", Materials \& Design, 92, pp. 787-793.

https://doi.org/10.1016/j.matdes.2015.12.064 while tooth root strength can be optimized by choosing CFR-PEEK or titanium alloys. Industrial practice supports these conclusions: for example Ti-6Al-4V and case hardened steel gear pairs are used in motor bicycles [16], or induction hardened steels in vehicle gearboxes.

\section{Conclusion}

Mass of gear pairs is strongly dependent on material properties. Gear related material parameters are pitting bearing capacity and tooth root strength. For rough selection of materials heuristic methods can be applied which are based on correspondences among material parameters and gear dimensions. New material selection strategy was introduced using Ashby model, generalizing the concept for gear materials. Results of analysis showed that the new charts are capable for selecting appropriate gear materials and ranking them. It was concluded that regarding pitting bearing capacity titanium and hardened steels give a minimum mass, and tooth root strength chart offered CFRPEEK or titanium as best option for gear pairs.

\section{Acknowledgement}

The project presented in this article is supported by the "Dynamics and control of autonomous vehicles in the synergy of demands for automated traffic systems" program in the frame of Széchenyi2020, Hungary, Grant No. EFOP-3.6.2-16-2017-00038.

[2] Gul, M., Celik, E., Gumus, A. T., Guneri, A. F. "A fuzzy logic based PROMETHEE method for material selection problems", Beni-Suef University Journal of Basic and Applied Sciences, 7(1), pp. 68-79, 2018.

https://doi.org/10.1016/j.bjbas.2017.07.002 
[3] Mousavi-Nasab, S. H., Sotoudeh-Anvari, A. "A comprehensive MCDM-based approach using TOPSIS, COPRAS and DEA as an auxiliary tool for material selection problems", Materials \& Design, 121, pp. 237-253, 2017.

https://doi.org/10.1016/j.matdes.2017.02.041

[4] Mousavi-Nasab, S. H., Sotoudeh-Anvari, A. "A new multi-criteria decision making approach for sustainable material selection problem: A critical study on rank reversal problem", Journal of Cleaner Production, 182, pp. 466-484, 2018.

https://doi.org/10.1016/j.jclepro.2018.02.062

[5] Gupta, K., Chatterjee, S. "Analysis of Design and Material Selection of a Spur gear pair for Solar Tracking Application", Materials Today: Proceedings, 5(1), pp. 789-795, 2018.

https://doi.org/10.1016/j.matpr.2017.11.148

[6] Ashby, M. F., Bréchet, Y. J. M., Cebon, D., Salvo, L. "Selection strategies for materials and processes", Materials \& Design, 25(1), pp. 51-67, 2004.

https://doi.org/10.1016/S0261-3069(03)00159-6

[7] Brechet, Y., Bassetti, D., Landru, D., Salvo, L. "Challenges in materials and process selection", Progress in Materials Science, 46(3-4), pp. 407-428, 2001.

https://doi.org/10.1016/S0079-6425(00)00019-0

[8] Singh, J., Mirjalili, V., Pasini, D. "Integrated shape and material selection for single and multi-performance criteria", Materials \& Design, 32(5), pp. 2909-2922, 2011. https://doi.org/10.1016/j.matdes.2010.11.076

[9] Albiñana, J. C., Vila, C. "A framework for concurrent material and process selection during conceptual product design stages", Materials \& Design, 41, pp. 433-446, 2012. https://doi.org/10.1016/j.matdes.2012.05.016

[10] Amany, A., Pasini, D. "Material and shape selection for stiff beams under non-uniform flexure", Materials \& Design, 30(4), pp. 11101117,2009

https://doi.org/10.1016/j.matdes.2008.06.029

[11] Wanner, A. "Minimum-weight materials selection for limited available space", Materials \& Design, 31(6), pp. 2834-2839, 2010. https://doi.org/10.1016/j.matdes.2009.12.052

[12] KISSoft AG "Gearbox Calculation Package GPK, The Standard for Industry Gearboxes" [online] Available at: http://www.kisssoft.ch/ english/downloads/gpk/Flyer-E.pdf [Accessed: 02 August 2017]
[13] Hartmann-Gerlach, C., Schulze, T. "Tutorial for gear design and calculation with MDESIGN gearbox", [pdf] DriveConcepts GmbH, Dresden, Germany, 2012, Available at: http://www. driveconcepts.com/info/tutorial_gearbox_2012_en.pdf [Accessed: 04 August 2017]

[14] Davies, J. R. "Gear Materials, Properties, and Manufacture", ASM International, Materials Park, OH, USA, 2010.

[15] Gligorijević, R., Jevtić, J., Borak, D. "Material Selection in Gear Design", ADEKO, Machine Design Journals, pp. 389-394, 2008.

[16] Baragetti, S. "Fatigue resistance of steel and titanium PVD coated spur gears", International Journal of Fatigue, 29(9-11), pp. 18931903, 2007. https://doi.org/10.1016/j.ijfatigue.2006.11.005

[17] Luo, J., Dong, H., Bell, T. "Model-based contact fatigue design of surface engineered titanium gears", Computational Materials Science, 35(4), pp. 447-457, 2006. https://doi.org/10.1016/j.commatsci.2005.03.013

[18] Talón, J. L. H., Ortega, J. C. C., Gómez, C. L., Sancho, E. R., Olmos, E. F. "Manufacture of a spur tooth gear in Ti-6Al-4V alloy by electrical discharge", Computer-Aided Design, 42(3), pp. 221-230, 2010 . https://doi.org/10.1016/j.cad.2009.11.001

[19] Liu, J., Cui, Z. "Hot forging process design and parameters determination of magnesium alloy AZ31B spur bevel gear", Journal of Materials Processing Technology, 209(18-19), pp. 5871-5880, 2009. https://doi.org/10.1016/j.jmatprotec.2009.06.015

[20] Mehta, D. S., Masood, S. H., Song, W. Q. "Investigation of wear properties of magnesium and aluminum alloys for automotive applications", Journal of Materials Processing Technology, 155156, pp. 1526-1531, 2004. https://doi.org/10.1016/j.jmatprotec.2004.04.247

[21] Dearn, K. D., Hoskins, T. J., Petrov, D. G., Reynolds, S. C., Banks, R. "Applications of dry film lubricants for polymer gears", Wear, 298-299, pp. 99-108, 2013. https://doi.org/10.1016/j.wear.2012.11.003 